\title{
THE DYNAMIC BEHAVIOUR OF BALLISTIC GELATIN
}

\author{
C. J. Shepherd ${ }^{1}$, G. J. Appleby-Thomas ${ }^{1}$, P. J. Hazell ${ }^{1}$, and D. F. Allsop ${ }^{1}$ \\ ${ }^{I}$ Cranfield Defence and Security, Cranfield University, Shrivenham, Swindon, SN6 8LA, UK
}

\begin{abstract}
In order to characterise the effect of projectiles it is necessary to understand the mechanism of both penetration and resultant wounding in biological systems. Porcine gelatin is commonly used as a tissue simulant in ballistic tests because it elastically deforms in a similar manner to muscular tissue. Bullet impacts typically occur in the $350-850 \mathrm{~m} / \mathrm{s}$ range; thus knowledge of the high strain-rate dynamic properties of both the projectile and target materials are desirable to simulate wounds. Unlike projectile materials, relatively little data exists on the dynamic response of flesh simulants. The Hugoniot for a $20 \mathrm{wt} . \%$ porcine gelatin, which exhibits a ballistic response similar to that of human tissues at room temperature, was determined using the plate-impact technique at impact velocities of $75-860 \mathrm{~m} / \mathrm{s}$. This resulted in impact stresses around three times higher than investigated elsewhere. In $U_{S}-u_{P}$ space the Hugoniot had the form $U_{S}=1.57+1.77 u_{P}$, while in $P-u_{P}$ space it was essentially hydrodynamic. In both cases this was in good agreement with the limited available data from the literature.
\end{abstract}

Keywords: Plate-impact, Shock, Hugoniot, Ballistic gelatin, Biological materials.

PACS: 43.25.Cb, 43.40.Ng, 43.80.Cs, 62.50.Ef.

\section{INTRODUCTION}

Human muscle is c. $75 \%$ water. Gelatin provides a method of suspending water in a solid, castable form. The resultant similarity in ballistic response to muscular tissue has led to the use of porcine gelatin dissolved at $20 \mathrm{wt} . \%$ in water as a flesh penetration simulant. While much previous work on this material has involved validation against low velocity penetration data [1,2], surprisingly little high strain-rate data beyond a limited $U_{S}-u_{P}$ Hugoniot [3] exists in the literature. In this paper a novel "cup" system is used to allow plate-impact experiments on as-cast 20 wt.\% gelatin targets, establishing a $U_{S}-u_{P}$ equation-ofstate in order to inform comparison of the simulant and actual tissue materials at high strain rates. This material equation-of-state provides useful information to aid the development of future hydrocode models to simulate tissue damage.

\section{EXPERIMENTAL PROCEDURE}

\section{Material properties}

A 250 bloom porcine gelatin (Weishardt International, France) mixed in water to $20 \mathrm{wt} . \%$ at c. $60{ }^{\circ} \mathrm{C}$, and subsequently allowed to set at room temperature, was employed in all tests. Density was measured to be slightly greater than water at $1.06 \pm 0.01 \mathrm{~g} / \mathrm{cm}^{3}$. Sound speeds were measured ultrasonically using a Panametrics 5077PR pulse receiver in the pulse-echo configuration combined with appropriate Panametrics $1.0 \mathrm{MHz}$ transducers. A longitudinal sound speed $\left(c_{L}\right)$ of $1.48 \pm 0.06$ $\mathrm{mm} / \mu \mathrm{s}$ was established, in good agreement with $c_{L}$ for water $(1.49 \mathrm{~mm} / \mu \mathrm{s}$ [4]). During plate-impact experiments gelatin acts hydrodynamically - i.e. as a fluid. It possesses negligible stiffness and is therefore unable to support a shear wave [4]. 


\section{Plate-impact experiments}

Plate-impact experiments [5-7] at 75-860 m/s were conducted using a $\varnothing 50-\mathrm{mm}$ bore single-stage gas gun [8]. Target material was cast into level cup containers, with a base comprising a c. $1 \mathrm{~mm}$ thick cover plate of the same material as the flyer plate. Careful measurement of the final as-cast thickness (3-10 mm) was made. Longitudinal manganin gauges (type LM-SS-125CH-048, manufactured by Vishay Micro-Measurements ${ }^{\circledR} \quad \& \quad$ SR-4 $\AA$ and calibrated according to [6]) were encapsulated within $25 / 50-\mu \mathrm{m}$ thick mylar layers as required and introduced either side of the target to monitor shock propagation. Shock velocity was subsequently determined based on the spatial separation of the two gauges. The rear surface gauge was backed by a 12-mm thick PMMA block, sized to allow mounting within the cup where the depth of gelatin was insufficient to reach the cup rim. The rear surface gauge package was adhered to the back face of the as-cast gelatin using a compatible fast-setting epoxy, before being bonded to the structural elements of the cup to enhance target package rigidity. All other elements of the target package were bonded using slow curing Loctite 0151 HYSOL $®$ Epoxi-Patch ${ }^{\circledR}$ Adhesive. Gauge analysis was performed according to the impedance matching technique [5-7]. A typical experimental setup is shown in Fig. 1. Impact velocities were measured by shorting a series of spatially separated velocity pins, while the target package was mounted on a target ring, itself mounted on a sacrificial barrel extension.

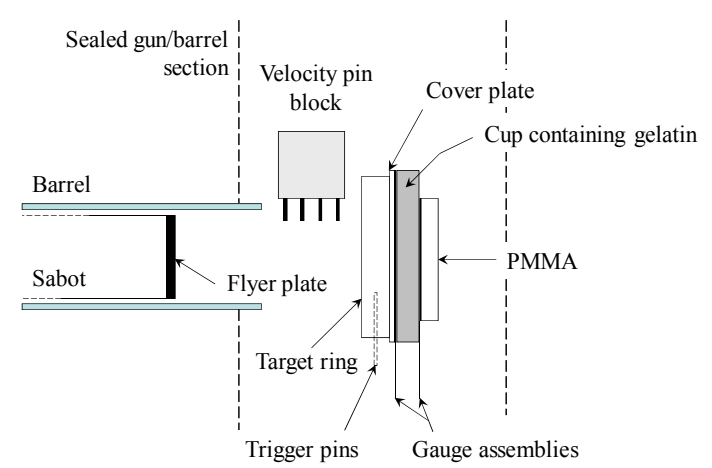

Figure 1. Plate-impact experimental setup.

\section{RESULTS AND DISCUSSION}

Nine shots using either PMMA, Dural or $\mathrm{Cu}$ flyers were undertaken according to the configuration shown in Fig. 1. Experimental results are summarised in Table 1. In one case front gauge failure prevented a $U_{S}-u_{P}$ point from being determined and, in another, insufficient confidence in the measured Hugoniot stress led to its exclusion from the results. Typical front and rear unfiltered gauge traces are presented for a 604 $\mathrm{m} / \mathrm{s}$ shot in Fig. 2. The rear surface trace has been rescaled to represent the approximate stress in the gelatin target based on the known Hugoniot of PMMA according to [7],

TABLE 1. Summary of experimental results.

\begin{tabular}{|c|c|c|c|c|c|}
\hline $\mathbf{v}_{\text {impact }}(\mathrm{m} / \mathrm{s})$ & Flyer material & $\begin{array}{c}\text { Flyer thickness } \\
(\mathbf{m m})\end{array}$ & $u_{P}(\mathrm{~mm} / \mu \mathrm{s})$ & $U_{S}(\mathbf{m m} / \mu \mathbf{s})$ & $\sigma_{X}(\mathbf{G P a})$ \\
\hline 75 & PMMA & 10 & 0.050 & 1.68 & 0.11 \\
\hline 112 & Dural & 10 & 0.091 & 1.68 & ---- \\
\hline 170 & $\mathrm{Cu}$ & 5 & 0.163 & 1.76 & 0.34 \\
\hline 199 & Dural & 10 & 0.166 & 1.95 & 0.24 \\
\hline 367 & Dural & 5 & 0.310 & 2.16 & 0.62 \\
\hline 546 & $\mathrm{Cu}$ & 10 & ---- & ---- & 1.26 \\
\hline 604 & $\mathrm{Cu}$ & 10 & 0.561 & 2.60 & 1.58 \\
\hline 804 & $\mathrm{Cu}$ & 10 & 0.746 & 2.67 & 2.33 \\
\hline 857 & $\mathrm{Cu}$ & 10 & 0.785 & 3.13 & 2.34 \\
\hline
\end{tabular}




$$
\sigma_{\text {gelatin }}=\frac{1}{2} \frac{\left(Z_{\text {gelatin }}+Z_{P M M A}\right)}{Z_{P M M A}} \sigma_{P M M A},
$$

where $\sigma_{\text {gelatin }}$ is the stress in the gelatin, $\sigma_{P M M A}$ is the stress in the PMMA, $Z_{\text {gelatin }}$ is the impedance of the gelatin and $Z_{P M M A}$ is the impedance of the PMMA. Where, $Z=\rho_{0} U_{S}, \rho_{0}$ is the material density and $U_{S}$ the shock velocity in the material measured from the shock transit time ( $\Delta$ t in Fig. 2).

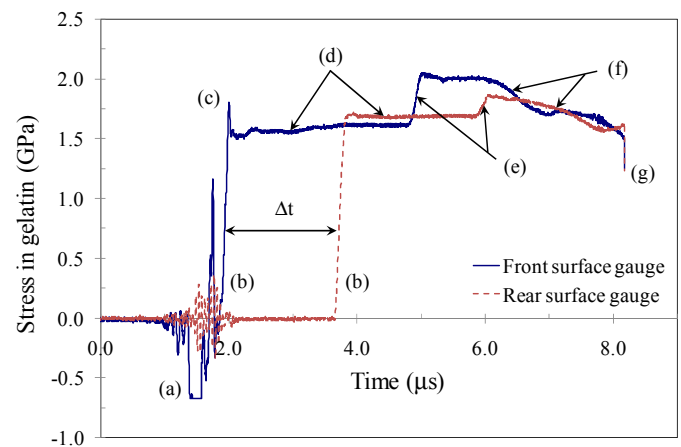

Figure 2. Front/rear gauges traces generated following impact of a $10-\mathrm{mm}$ thick $\mathrm{Cu}$ flyer at $604 \mathrm{~m} / \mathrm{s}$ onto a 4.6 $\mathrm{mm}$ thick gelatin target following Fig. 1 .

Both traces in Fig. 2 showed a rapid rise (b) to a Hugoniot stress (d) followed by a reloading (e) and subsequent elastic release (f) before gauge failure $(\mathrm{g})$. An initial undershoot on the front surface gauge just before shot arrival at (a) has been linked elsewhere [9] to an increase in capacitance between the gauge and cover plate as the cover plate is accelerated towards the gauge. Gauge rise times (b) were relatively slow compared to a typical longitudinal gauge response [7] at 144 and $170 \mathrm{~ns}$ on the front and rear gauges respectively. This was due to the difficulty of ensuring an intimate contact with the as-cast gelatin. Nevertheless, these rise times were comparable and sufficiently sharp to indicate a good impedance match between the manganin gauges and their encapsulation. Further, rise durations were small compared to the temporal shock lifetime. Following the rise on the front surface gauge, ringing within the gauge encapsulation just before the Hugoniot plateau resulted in an overshoot above the Hugoniot stress (c). Good correlation between the constant Hugoniot stress values on both gauges (d) followed reduction of the rear surface data using Equation
(1). A consequent difference in stress magnitude of $<5 \%$ between the two plateaus confirmed the validity of the stress measurements. Finally, reloading above the original Hugoniot stress on both gauges at (e) is due to shock reverberation $[10,11]$ - i.e. ringing between the higher impedance $\mathrm{Cu}$ cover and PMMA backing which encapsulated the lower impedance target gelatin.

$U_{S}-u_{P}$ and $P-u_{P}$ Hugoniot relationships based on Table 1 are presented in Figs. 3 and 4 respectively. Errors were calculated in different ways. For $U_{S}$ and $u_{P}$ they were based on the range of possible shock arrival times ( $\Delta \mathrm{t}$ in Fig. 2 ) and were typically $<0.4$ and $0.01 \mathrm{~mm} / \mu \mathrm{s}$ respectively. For $\sigma_{X}$, the errors represented variations across the measured Hugoniot plateaus and were consistently $<0.1 \mathrm{GPa}$. For comparison, the limited available literature data on $20 \mathrm{wt} . \%$ gelatin is also included in Fig. 3 [3].

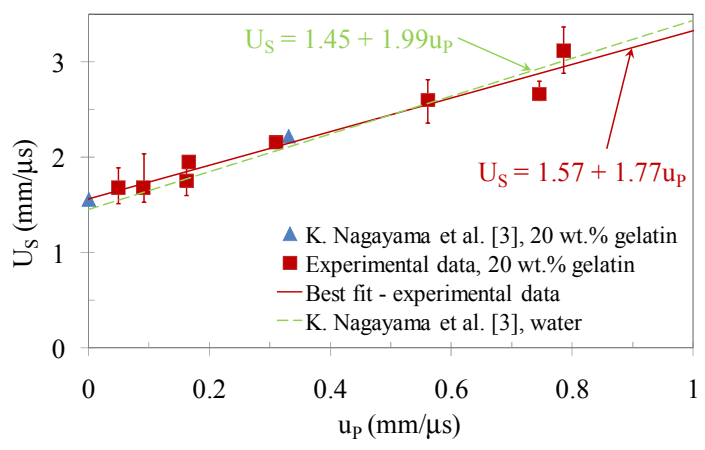

Figure 3. $U_{S^{-}} u_{P}$ Hugoniot, 20 wt.\% gelatin.

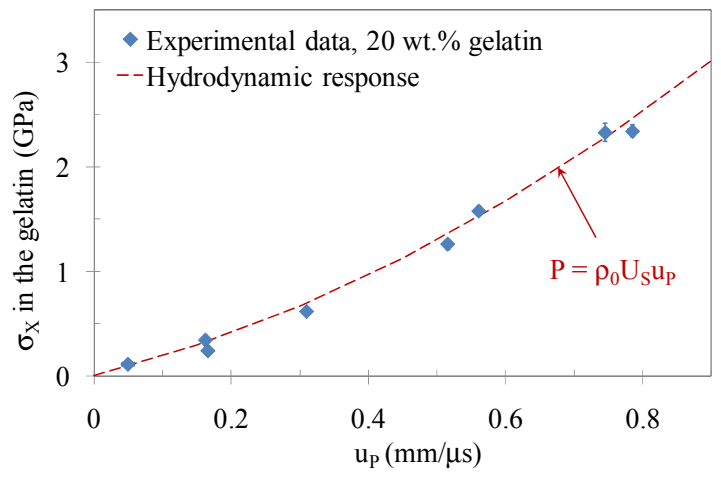

Figure 4. $P-u_{P}$ Hugoniot, $20 \mathrm{wt} . \%$ gelatin.

The $U_{S^{-}} u_{P}$ Hugoniot in Fig. 3 is in good agreement with the two available data points for 20 
wt.\% gelatin from Nagayama et al. [3]. Further, within the error bars the experimental Hugoniot for 20 wt.\% gelatin and that for water from [3] are extremely similar. This implies that gelatin behaves entirely hydrodynamically under shock loading. Unlike strong materials where $\mathrm{U}_{\mathrm{S}}$-axis intercept normally occurs at the bulk sound speed [5], with gelatin, the intercept occurs at a similar velocity to the longitudinal sound speed (e.g. 1.45 $\mathrm{mm} / \mu \mathrm{s}$, compared to a measured $c_{L}$ of $1.48 \pm 0.06$ $\mathrm{mm} / \mu \mathrm{s})$. Fig. 4 includes a theoretical curve, based on the $U_{S}-u_{P}$ Hugoniot set out in Fig. 3, which predicts the behaviour of the gelatin assuming that it behaves hydrodynamically [9]. Good agreement is observed between the experimental data and the hydrodynamic response.

\section{CONCLUSIONS}

A novel technique which allows 1D plateimpact experiments to be carried out on gel-based materials has been successfully implemented using 20 wt.\% porcine gelatin. $U_{S}-u_{P}$ and $P-u_{P}$ Hugoniot relationships have been established for this material. Good agreement between the measured $U_{S}-u_{P}$ relationship and the limited literature data available enhanced confidence in the technique. The importance of this result was emphasised by the fact that the type of gelatin employed is well defined, whereas the source of the material described in the literature is unclear. Comparison of the measured Hugoniot to that for water as well as ultrasonic measurements of elastic properties indicated that under high strain rates the as-cast gelatin behaves hydrodynamically (e.g. it exhibits no significant shear strength).

Overall, the equations-of-state set out in this paper greatly enhance the availability of materials data for hydrocode models designed to compare the response of ballistic penetration simulants with actual biological tissues. When combined with a knowledge of ballistic tests (to allow calibration of strength elements of material models), this data should minimise the requirement for testing on biological tissues.

\section{ACKNOWLEDGEMENTS}

The authors wish to thank both Gary Cooper for experimental support and ARUP for provision of both funding and support.

\section{REFERENCES}

1. Jussila, J., "Preparing Ballistic Gelatine - Review and Proposal for a Standard Method", For. Sci. Int. 141(2-3), 91, 2004.

2. Sellier, K. G. and Kneubuehl, B. P., "Wound Ballistics and the Scientific Background", Elsevier, Amsterdam, 1994.

3. Nagayama, K., Mori Y., Motegi, Y. and Nakahara, M., "Shock Hugoniot Compression Data for Several Bio-related Materials", in Shock Compression of Condensed Matter, 2005 (M.D. Furnish, M. Elert, T.P. Russell, C.T. White, eds.), part II, pp. 15471550 .

4. White, F. M., "Fluid Mechanics", McGraw-Hill, Inc., USA, 1979.

5. Meyers, M. A., "Dynamic Behaviour of Materials", John Wiley \& Sons Inc., New York, 1994.

6. Rosenberg, Z., Yaziv D. and Partom, Y., "Calibration of foil-like manganin gauges in planar shock wave experiments", J. Appl. Phys. 51(7), 3702, 1980.

7. Appleby-Thomas, G. J., Hazell, P. J., Stennett, C., Helaar, K. and Diederen, A. M., "Shock propagation in a cemented tungsten carbide", J. Appl. Phys. 105, 064916, 2009.

8. Bourne, N. K., "A $50 \mathrm{~mm}$ bore gas gun for dynamic loading of materials and structures", Meas. Sci. \& Tech. 14, 273, 2003.

9. Hazell, P. J., Stennett, C. and Cooper, G., "The Shock and Release Behavior of an Aerospace-Grade Cured Aromatic Amine Epoxy Resin", Polymer Composites 29(10), 1106, 2008.

10. Kondo, K., Yasumoto, Y., Sugiura, H. and Sawaoka, A., "Multiple shock reverberations in a layer structure observed by particle-velocity and pressure gauges", J. Appl. Phys. 52(2), 772, 1981.

11. Winter, R. E., Whiteman, G., Haining, G. S., Salisbury, D. A. and Tsembelis, K., "Measurement of Equation of State of Silicone Elastomer", in Shock Compression of Condensed Matter, 2003 (M.D. Furnish, Y.M. Gupta, J.W. Forbes, eds.), part I, pp. 679-682. 